\title{
Thermo-kinetic, spectroscopic study of brewer's spent grains and characterisation of their pyrolysis products
}

\author{
Ayokunle O. Balogun $^{\mathrm{a}, *}$, Farid Sotoudehniakarani ${ }^{\mathrm{b}}$, Armando G. McDonald ${ }^{\mathrm{b}}$ \\ a Department of Mechanical Engineering, College of Science \& Engineering, Landmark University, P.M.B. 1001, Omuaran, Nigeria \\ b Department of Forest, Rangeland and Fire Sciences, University of Idaho, Moscow, ID 83844-1132, USA
}

\section{A R T I C L E I N F O}

\section{Keywords:}

Brewer's spent grains

Pyrolysis

Kinetic behaviours

Product characterisation

Transesterification

\begin{abstract}
A B S T R A C T
Brewer's spent grains, major by-products of the beverage industries, were obtained from a Nigerian brewery and subjected to pyrolysis at $500{ }^{\circ} \mathrm{C}$. Analytical pyrolysis (Py-GC/MS) was conducted on the original BSG, extractivefree BSG and BSG $\mathrm{CH}_{2} \mathrm{Cl}_{2}$ extract. There was a marked difference in the concentration of levoglucosan between the extractive-free BSG (40.5\%) and the original BSG (11.5\%). The Py-GC/MS detected significant amount of palmitic and oleic acids in the three samples. Prior to pyrolysis, the extractives content were isolated through methanolysis, transesterified and subjected to GC/MS analysis. The analysis revealed the presence of linoleic, oleic and palmitic acids in an appreciable quantity. The BSG and its biochar were also characterised according to Fourier transform infrared and Raman spectroscopic, and thermogravimetric analyses alongside some conventional physico-chemical analysis. The total crystallinity and condensation indices were evaluated from specific FTIR spectra peaks so as to monitor structural transformations in the bio-char. Kinetic data were deduced from TGA measurements and it was apparent that thermal decomposition of BSG is better modelled as a multi-step reaction mechanism. The nitrogen content of the bio-char was relatively high making it a suitable feedstock for the production of in situ nitrogenised activated bio-carbon. There was a significant variation between the structural configuration of the original BSG and the bio-char as revealed by the change in the value of the condensation index as well as the cellulose crystallinity content. It may thus be concluded that the BSG biomass would be a viable feedstock for thermal decomposition and other valorisation processes.
\end{abstract}

\section{Introduction}

Lately, the sustainable utilisation of energy resources and waste management techniques are critical environmental issues that have elicited global concern. This concern has risen from the hazardous impact of diverse anthropogenic activities. Biomass being a renewable and sustainable resource has attracted sustained interest for two primary reasons: its prospect in (1) addressing waste management challenges, and (2) bioenergy applications. Biomass is reputed for environmental compatibility, economic viability, widespread availability and huge abundance as wastes and by-products from several agro-industrial processes. For example, the Nigerian brewing sector that depends largely on malted barley, sorghum and maize for beverages production churns out huge amount of biomass residues annually. As these grains undergo the beneficiation processes, one of the agro-industrial residues often generated are the brewer's spent grains (BSG). The BSG represents about $85 \%$ of the total by-product of the brewing process with an annual global production of $30 \times 10^{6}$ tonnes [1]. According to Deconinck et al. [2] and Mussatto et al. [3] an estimate of
0.14-0.20 kg of wet BSG (20-25 wt $\%$ dry matter) is generated for every $1 \mathrm{~L}$ of beer. Therefore, for the Nigerian brewing sector with an installed capacity of $2.7 \times 10^{9} \mathrm{~L}$, a considerable amount of $38-54 \times 10^{3}$ tonnes could be generated when in full production capacity [4].

The BSG is a lignocellulosic residue obtained from the mashing and filtration of the malting grains to produce maltose from starch for fermentation. BSG is primarily used for the preparation of animal feeds because of its high fibre $(60 \%)$ and protein $(20 \%)$ contents [5]. However, the huge amount of BSG generated cannot be moped up by this single stream of application. Furthermore, the high moisture content associated with wet BSG makes it highly susceptible to microbial activity; jeopardising storage and escalating transportation cost. From the foregoing, the continuous generation of BSG has raised significant environmental and economic concerns; thus necessitating the search for alternative uses $[1,3,6]$. Being a lignocellulosic material, composed of an intricate matrix of cellulose and hemicellulose polysaccharides, lignin and extractives, it could be an ideal feedstock for thermochemical conversion and other valorisation processes [6-8].

Biomass extractives are non-structural components. Though they

\footnotetext{
* Corresponding author.

E-mail address: olubusayo2@gmail.com (A.O. Balogun).
} 
occupy a relatively small proportion of the matrix, they may be isolated as renewable feedstock for varied applications. In pharmaceutical applications, the therapeutic effects of extracts from biomass have been underscored [8]. Lipid extracts may serve as raw materials for biodiesel production. Researchers have undertaken scientific investigations into the transesterification process for biodiesel production from diverse biomass sources [9-11]. Furthermore, phytochemicals and bio-lubricants may be derived from the constituents of extractives $[3,12]$. In this study lipid extracts will be isolated from BSG, transesterified into fatty acid methyl esters (FAME) and subjected to GC/MS analysis.

Pyrolysis is a prominent thermal technology because of its relatively low capital investment and its potential to produce three distinctive final products (non-condensable gases, liquid organics and solid residues) that are suitable for various applications. The use of wet BSG sample for pyrolysis raises the energy requirement in terms of the enthalpy of vaporisation necessary for moisture evaporation. It has been noted that microbial treatment of breweries waste water generates methane. This may be burned and used as a heat source for drying the solid wet stream prior to the thermal process $[13,14]$. Furthermore, the gaseous product can be recycled and combusted to dehydrate the biomass feedstock as well as improve the thermal efficiency of the pyrolytic reactor [15]. The biochar is a viable source of energy which may be exploited as fuel for heating applications and/or co-firing purposes. In addition, it could find significant use in promoting sustainable agricultural practices and environmental management issues as carbon sequesters, soil amendment media and adsorbents [16-18].

Bio-oil can either be used directly or upgraded through catalytic means to fuels and other valuable products that are compatible with existing petroleum infrastructures $[19,20]$. Biomass feedstock type significantly influences the chemical composition of the liquid product; which is a crucial consideration in the prospective application of biooil. Typically, bio-oil is composed of a wide variety of chemical compounds in varying quantities. However, they may be broadly classified as hydroxyaldehydes, hydroxyketones, carboxylic acids, furan/pyran ring containing compounds, anhydrosugars, phenolic compounds, and oligomeric fragments of lignocellulosic polymers $[16,21]$. These compounds are products of complex multiple reactions, which may include a combination of dehydration, polymerisation, re-polymerisation and condensation, often following parallel and successive pathways. In addition, the intricate structure of lignocellulosic biomass that consists of interpenetrating network of polymeric fractions, extractives, ash and other compounds also contributes to the characteristic nature of pyrolysis bio-oil. This underscores the importance of identification and quantification of the detectable chemical compounds in the liquid product. This study undertook limited study of BSG pyrolysis because of the scarce amount of BSG sample that prevented replicate and detailed bio-oil investigations. Therefore the article reports analytical pyrolysis (Py-GS/MS) data only.

Prior to the deployment of biomass resources for bioenergy purposes it is common to subject them to some basic data characterisation exercises so as to gain insight into their physical and chemical properties. Traditionally, the proximate, ultimate, compositional analyses and calorific value determination are used and they offer insightful empirical information [22,23]. Another characterisation technique often deployed is the thermogravimetric analysis (TGA). It is a powerful thermo-analytical tool for prospecting the thermal decomposition behaviour of most lignocellulosic resources. The TGA data is valuable in developing mathematical models that can predict the decomposition mechanisms of the respective polymeric fractions. Balogun et al. [24], Lopez-Velaquez et al. [25] and Burhenne et al. [26] have all developed mathematical models from TGA data, which were subsequently used in evaluating the kinetic parameters for some biomass materials.

Non-destructive analytical techniques can shed light on structural configurations/modifications and functional groups of lignocellulosic biomass. The Fourier transform infra-red (FTIR) spectroscopic data could be used to monitor chemical and structural transformations in thermally decomposed biomass materials. Da Silva et al. [27] in their study of immobilisation of commercial laccase on beer's spent grains and dos Santos et al. [6] in the preparation of carboxymethyl cellulose from cellulose extracted from brewer's spent grains undertook FTIR analysis. Ferraz et al. [28] also monitored the changes in the biomass composition during the study of chromium (III) biosorption onto spent grains residues obtained from a Portuguese brewing industry. Further studies on the FTIR spectroscopy of BSG include that of Montusiewicz et al. [29] Becidan et al. [18], and Xi et al. [30]. Other analyses include Raman spectroscopy and X-ray diffraction (XRD), which could be deployed to investigate the structure of carbon and deduce the degree of cellulose crystallinity respectively [31,32]. To the best of the authors' knowledge there is little information on research investigation in to the structural composition of thermally decomposed BSG samples. Therefore, the aim of this study was to obtain lipid extracts from BSG and subject them to transesterification and GC/MS analysis. Furthermore, the BSG samples will be pyroylsed and the biochars characterised.

\section{Experimental}

\subsection{Sample preparation}

BSG was obtained from International Brewery Plc, Ilesha, Nigeria in June 2016 about $4 \mathrm{~h}$ after the brewing process. The feedstock for the brewing process was a mixture of maize grit and malted barley. The BSG was oven dried at $100{ }^{\circ} \mathrm{C}$ for $18 \mathrm{~h}$, ground in a Thomas Wiley mill (model 4) to pass through a $1 \mathrm{~mm}$ screen and stored in Ziploc bags. Samples for TGA analysis were further ground to a fine powder in a mortar and pestle and particle. Optical microscopy was performed on (i) BSG and (ii) the mortar and pestle ground BSG on an Olympus BX51 microscope equipped with a DP70 digital camera at $40 \mathrm{x}$ and $100 \mathrm{x}$ magnification, respectively Particle length measurements were performed on 308 particles for each sample. Original BSG particle size ranged between 16 and $1038 \mu \mathrm{m}$ with an average of $168 \mu \mathrm{m}$ (standard deviation $191 \mu \mathrm{m}$ ). The mortar and pestle ground BSG particle size, used for TGA analysis, ranged between 5.7 and $297 \mu \mathrm{m}$ with an average $39 \mu \mathrm{m}$ (standard deviation $36 \mu \mathrm{m}$ ).

\subsection{Biomass characterisation}

The BSG moisture content was determined by an HB 43-S Mettler Toledo moisture analyser (Ohio, USA), while the determination of the volatile matter $(\mathrm{VM})\left(950^{\circ} \mathrm{C}\right.$ for $\left.7 \mathrm{~min}\right)$ and ash contents $\left(600{ }^{\circ} \mathrm{C}\right.$ for $16 \mathrm{~h}$ ) were determined according to BS EN 15148 and D1102-84, respectively [22]. The fixed carbon (FC) content was subsequently evaluated by difference. The ultimate analysis was conducted on a Costech ESC 4010 elemental analyser for the determination of Cand $\mathrm{N}$ contents. The higher heating value (HHV) determination was carried out in a Parr oxygen bomb calorimeter model 1341 according to ASTM D5865-04 in triplicate and calibrated with benzoic acid [22]. The charging of the bomb was preceded by the production of BSG pellets ( $\approx 1.0 \mathrm{~g}, \emptyset 6 \mathrm{~mm})$ on a Carver laboratory hydraulic press at 13.8 MPa.

Chemical composition analysis (extractives, lignin and neutral carbohydrate content) of BSG were determined in duplicate. Briefly, BSG (4-5 g) was Soxhlet extracted with $\mathrm{CH}_{2} \mathrm{Cl}_{2}(150 \mathrm{~mL}$ ) for $24 \mathrm{~h}$ according to ASTM D1108-96 and the extractives (lipids) were determined gravimetrically. Lignin content (Klason lignin plus acid soluble lignin) was determined according to ASTM D 1106-96 and Schoening and Johansson, respectively. More specifically, dried BSG (200 mg) was incubated in $72 \% \mathrm{H}_{2} \mathrm{SO}_{4}(2 \mathrm{~mL})$ for $1 \mathrm{~h}$ at $30{ }^{\circ} \mathrm{C}$, then diluted into $4 \%$ $\mathrm{H}_{2} \mathrm{SO}_{4}$, and subjected to a secondary hydrolysis in an autoclave (117 $\mathrm{KPa}$ and $121^{\circ} \mathrm{C}$ ) for $30 \mathrm{~min}$. The hydrolysate was filtered to obtain Klason lignin content gravimetrically. The hydrolysis filtrate was made up to $250 \mathrm{~mL}$ and an aliquot portion taken to determine acid soluble lignin fraction content at $205 \mathrm{~nm}$ using an absorption coefficient of $110 \mathrm{~L} \mathrm{~g}^{-1} \mathrm{~cm}^{-1}$ (Biomate 5, Thermoelectron). Carbohydrate analysis 
was performed on the 2-stage acid-hydrolysates according to ASTM E 1758-01. An aliquot portion of the hydrolysate $(5 \mathrm{~mL})$ was transferred to a centrifuge tube to which internal standard (inositol, $1 \mathrm{~mL}$, $0.5 \mathrm{mg} \mathrm{mL}^{-1}$ ) and $\mathrm{PbCO}_{3}(0.16 \mathrm{~g})$ were added, mixed well, centrifuged, and the supernatant $\left(4 \mathrm{~mL}\right.$ ) deionized (column of Amberlite IR-120H ${ }^{+}$ $(0.5 \mathrm{~mL})$ and Amberlite IRA35 $\mathrm{OH}^{-}(0.5 \mathrm{~mL})$ resins) and filtered $(0.45 \mu \mathrm{m})$ into HPLC vials. Monosaccharides were the quantified by HPLC using two RPM columns in series $(7.8 \mathrm{~mm} \times 30 \mathrm{~cm}$, Phenomenex) at $85{ }^{\circ} \mathrm{C}$ equipped with differential refractive index detector (Waters Associates model 2414) on elution with $0.5 \mathrm{~mL} \mathrm{~min}^{-1}$ water.

\subsection{Fatty acids methyl esters (FAME) preparation and analysis}

$2 \mathrm{~mL}$ of $\mathrm{CH}_{3} \mathrm{OH} / \mathrm{H}_{2} \mathrm{SO}_{4} / \mathrm{CHCl}_{3}(1.7: 0.3: 2.0 \mathrm{v} / \mathrm{v} / \mathrm{v})$ was added to the $\mathrm{CH}_{2} \mathrm{Cl}_{2}$ extract $(2 \mathrm{mg})$ and the mixture heated for $90 \mathrm{~min}$ at $90{ }^{\circ} \mathrm{C}$ to form the FAME derivatives [22]. $\mathrm{CHCl}_{3}$ contained 1-napthalaneacetic acid as an internal standard $\left(100 \mu \mathrm{g} \mathrm{mL}{ }^{-1}\right)$. The FAME derivatives were subjected to analysis in a GC-MS (FOCUS-ISQ, ThermoScientific); here separation was in a ZB $5 \mathrm{~ms}$ capillary column $(30 \mathrm{~m}, 0.25 \mathrm{~mm} \varnothing$, Phenomenex) at a temperature profile of $40{ }^{\circ} \mathrm{C}(1 \mathrm{~min})$ to $320^{\circ} \mathrm{C}$ and at $5{ }^{\circ} \mathrm{C} \mathrm{min}{ }^{-1}$. The eluted compounds were identified with authentic $\mathrm{C}_{12}$ to $\mathrm{C}_{20}$ fatty acid standards and by spectral matching with the 2008 NIST mass spectral library.

\subsection{Thermogravimetric analysis (TGA), Raman and Fourier transform infrared (FTIR) spectroscopy, and X-ray diffraction (XRD)}

The BSG sample was subjected to TGA and FTIR spectroscopic analyses according to international standards as detailed in an earlier publication $[33,34]$. The TGA data were gathered on a Perkin Elmer TGA-7 instrument at multiple heating rates of $5,20,30$ and $50 \mathrm{~K} / \mathrm{min}$. The FTIR spectroscopy analysis of the original vacuum dried BSG and the bio-char was conducted on an is5 spectrometer (ThermoNicolet) in the single bounce attenuated total reflection (ATR) mode (iD5, ZnSe). The lignin condensation index (CI) was evaluated by dividing the sum of all the spectra minimum peak intensities between 1500 and $1050 \mathrm{~cm}^{-1}$ by the sum of all the spectra maximum peak intensities between 1600 and $1030 \mathrm{~cm}^{-1}$ [33,35]. Furthermore, cellulose crystallinity as total crystalline index (TCI) were computed from the relative peak intensities about 1429 and $897 \mathrm{~cm}^{-1}$. The BSG biochar was analysed by Raman spectroscopy on 5 replicates on an Alpha $300 \mathrm{R}$ confocal Raman microscope (Witec) spectrometer with $532 \mathrm{~nm}$ excitation, $0.5 \mathrm{~s}$ integration time and 5 scans. The spectra were averaged and baseline corrected using Omnic v9 (ThermoScientific) software. BSG cellulose crystallinity was determined by XRD (Siemens D5000 diffractometer) scanning $2 \theta$ from 5 to $50^{\circ}$ with steps of $0.2^{\circ}$. The diffractogram was peak fitted using IGOR Pro v6.3 software prior to determination of cellulose crystallinity index (CCI). CCI was determined from the ratio of the integral intensities, after peak fitting and amorphous baseline subtraction, of crystalline portions to the total intensity of sample according to $\mathrm{CCI}=\left(1-\left(\mathrm{I}_{\mathrm{am}} / \mathrm{I}_{002}\right)\right)$, where $\mathrm{I}_{\mathrm{am}}$ is the intensity of the peak at $2 \theta=18^{\circ}$ and $\mathrm{I}_{002}$ is the maximum intensity of the (002) plane diffraction at $2 \theta=22^{\circ}$ [32].

\subsection{Kinetic study}

The global kinetic model for solid-state thermal decomposition is expressed as a function of Arrhenius rate equation and degree of conversion according to the mathematical relation in Eq. (1).

$\frac{d \alpha}{d t}=\operatorname{Aexp}\left({ }^{E}{ }^{E} / R T\right) f(\alpha)$

Where $R$ is the universal gas constant $\left(8.314 \mathrm{~J} \mathrm{~mol}^{-1} \mathrm{~K}\right), \alpha$ is the degree of conversion and $f(\alpha)$ is the reaction model, $E_{a}$ is the apparent activation energy $\left(\mathrm{J} \mathrm{mol}^{-1}\right), T$ is the temperature (K) and $t$ is time (min).
Applying the integral method to Eq. (1), yields a temperature integral that is not amenable to an analytical solution. The temperature integral is often linearized through a couple of approximation techniques [36]. Starink [37] examined two of such techniques (Flynn-Wall-Ozawa and Kissinger-Akhira-Sunose) and optimized them to obtain the expression in Eq. (2).

$\ln \left(\frac{\beta}{T^{1.8}}\right)=$ constant $-1.0037 \frac{E_{a}}{R T}$

Where $\beta$ is the heating rate $(\mathrm{K} / \mathrm{min})$. Unlike the previous method, the differential method does not require any approximations. It assumes a constant degree of conversion and thus the reaction rate proceeds only as a function of temperature. Sequel to a series of mathematical manipulations of Eq. (1), the Friedman's method, as shown in Eq. (3), is obtained.

$\ln \left(\frac{d \alpha}{d t}\right)_{\alpha}=$ constant $-\frac{E_{a}}{R T}$

For this study, the apparent activation energy will be calculated from the linear plots of both the integral and differential methods.

\subsection{Pyrolysis of BSG residues}

Pyrolysis experiment was performed in an auger reactor $(\varnothing 5 \mathrm{~cm} \mathrm{x}$ $90 \mathrm{~cm})$ at $0.5 \mathrm{~kg} \mathrm{~h}^{-1}$ dried BSG feed rate, and $500{ }^{\circ} \mathrm{C}$ in an inert environment created by an $\mathrm{N}_{2}$ flow $\left(6 \mathrm{~L} \mathrm{~min}{ }^{-1}\right)$. The auger speed was adjusted to obtain an $8 \mathrm{~s}$ residence time. The bio-oil was recovered through vapour quenching in a dual-stage ice-water-cooled tube and shell heat exchanger. Bio-char was collected at the other end of the reactor and yield recorded. Gas yield was determined by difference [17]. However, due to the limited amount of BSG sample the pyrolysis experiments could not be performed in replicates and other temperature values. Hence the report was limited to bio-char characterisation and analytical pyrolysis (Py-GC/MS) as presented below

\subsection{Analytical pyrolysis and bio-char characterisation}

Analytical pyrolysis GC-MS analysis on BSG were performed on a Pyrojector II unit (SGE Analytical Science) at $500{ }^{\circ} \mathrm{C}$ in an inert atmosphere (He, 0.125 MPa) coupled to a GC-MS instrument, as in Section 2.3 , but using a temperature profile of $50{ }^{\circ} \mathrm{C}(1 \mathrm{~min})$ to $320^{\circ} \mathrm{C}$ and at $5{ }^{\circ} \mathrm{C} \min ^{-1}$. Bio-char samples were dried in an oven at $104^{\circ} \mathrm{C}$ for $24 \mathrm{~h}$ prior to analysis. The physico-chemical properties for the bio-char were determined as described in Section 2.2 and further analyses as stated in a previous publication [17]. The butane activity (BA) was determined according to ASTM D5742-95. Bio-char (16.7 mL, of known weight) was placed into the sample tube, flushed with butane $\left(250 \mathrm{~mL} \mathrm{~min}^{-1}\right)$ until a constant weight gain was obtained at $25^{\circ} \mathrm{C}$. The surface area of the biochar $\left(0.25 \mathrm{~g}\right.$, degassed for $30 \mathrm{~min}$ at $\left.200{ }^{\circ} \mathrm{C}\right)$ was determined using $30 \% \mathrm{~N}_{2}$ in He with a ChemiSorb 2720 analyzer (Micromeritics Instrument Corporation) in duplicate.

\section{Results and discussion}

3.1. Biomass characterisation through physico-chemical analysis and HHV determination

A necessary preliminary step in the application of lignocellulosic resources for bioenergy purposes is a basic characterisation process, which often includes a combination of physical and chemical analyses. The results of such analyses give valuable insight into prospective applications and may also offer explanation on some distinctive thermal behaviour during thermochemical conversion processes. Table 1 presents the physico-chemical analysis and HHV determination for BSG residues as compared with other agricultural/agro-industrial biomass 
Table 1

Physico-chemical analysis, and HHV for BSG and BSG biochar.

\begin{tabular}{|c|c|c|c|c|c|}
\hline Physico-chemical analysis ${ }^{a}$ & BSG & BSG-biochar & BSG-A & BSG-B & BSG-C ${ }^{c}$ \\
\hline VM (\%) & $77.13 \pm 0.32$ & $29.98 \pm 0.32$ & & & 78 \\
\hline Ash (\%) & $3.83 \pm 0.05$ & $13.17 \pm 0.13$ & 2.4 & 4.6 & 4.5 \\
\hline $\mathrm{FC}(\%)^{\mathrm{d}}$ & $19.03 \pm 0.38$ & $56.85 \pm 0.45$ & & & 9.5 \\
\hline $\mathrm{C}(\%)$ & $49.2 \pm 0.09$ & $65.50 \pm 1.00$ & & & 46.6 \\
\hline N (\%) & $3.48 \pm 0.02$ & $5.62 \pm 0.22$ & & & 3.54 \\
\hline $\mathrm{CH}_{2} \mathrm{Cl}_{2}$ extract (\%) & $11.82 \pm 0.55$ & & 10.6 & - & 34.8 \\
\hline Glucan/cellulose (\%) & $26.3 \pm 0.6$ & & 25.4 & 16.8 & 19.0 \\
\hline Xylan (\%) & $13.5 \pm 0.5$ & & 21.8 & 28.4 & 33.6 \\
\hline Arabinan (\%) & $5.3 \pm 0.1$ & & & & \\
\hline Galactan + mannan (\%) & $0.9 \pm 0.1$ & & & & \\
\hline Total neutral carbohydrate (\%) & $46.0 \pm 1.3$ & & & & 52.6 \\
\hline Klason lignin (\%) & $10.11 \pm 0.19$ & & 11.9 & 27.8 & 12.6 \\
\hline Acid soluble lignin (\%) & $3.69 \pm 0.07$ & & & & \\
\hline HHV (MJ/kg) & $21.67 \pm 0.21$ & $25.97 \pm 0.11$ & & & - \\
\hline Surface area $\left(\mathrm{m}^{2} / g\right)$ & & $3.12 \pm 0.09$ & & & \\
\hline Butane activity(\%) & & $1.78 \pm 0.03$ & & & \\
\hline
\end{tabular}

${ }^{\mathrm{a}}$ dry-basis.

b [3].

c [7].

d calculated by difference.

samples from literature.

The physico-chemical data for the BSG being studied showed that the values for most of the parameters conform appreciably to the range reported in literature $[7,22]$. For example, the $\mathrm{N}$ content for the BSG (3.48\%) was comparable to the one found in literature with an estimated protein content of $22 \%$ [7]. The BSG could therefore serve as a feedstock for the production of an in situ nitrogenised activated biocarbon [1]. The $\mathrm{CH}_{2} \mathrm{Cl}_{2}$ extractives content for the BSG in this study was a third of that in the literature [7]. Apparently, the difference in the extraction method accounts for this variation. The main carbohydrates in BSG were cellulose (26\%) and arabinoxylan (19\%) and this makes BSG an amenable feedstock for cellulosic ethanol production. The energy content as revealed by the HHV for BSG is relatively high for a lignocellulosic biomass and thus promises to be a viable feedstock for thermal decomposition process such as pyrolysis. This has been corroborated in a study [38].

The biochar showed an increase in the FC and C contents over BSG, which consequently led to significant rise $(\approx 20 \%)$ in the HHV. The improved energy content makes the bio-char a suitable fuel source in industrial heating applications either as co-combustion or combustion in furnaces and boilers. It is also noteworthy that the bio-char being relatively high in $\mathrm{C}$ and $\mathrm{N}$ contents could serve as a medium for soil fertility improvement and carbon sequestration. In comparison to activated carbon the butane activity (indirect measure of adsorption of alkane) for the bio-char is much lower and this may be attributed to a low surface area $\left(3.1 \mathrm{~m}^{2} / \mathrm{g}\right)$ arising from a relatively less intensive thermal treatment [17].

\subsection{TGA and kinetic data}

The thermal decomposition behaviour of BSG and extractive-free BSG at $20 \mathrm{~K} / \mathrm{min}$ as a function of temperature is shown in Fig. 1. The thermograms broadly revealed three main stages of decomposition with the highest mass loss experienced between approximately 600 and $873 \mathrm{~K}$. It is noteworthy that the pyrolysis temperature for most biomass resources lie within this temperature interval $[17,19,21]$; here a wide variety of volatile organic species are liberated from the decomposition of the main components, lignin and polysaccharides, as identified in Table 1. The earliest decomposition stage corresponds to moisture evaporation and liberation of light organic volatiles, while the trailing stage indicates lignin decomposition. Apparently, the original BSG sample possesses a very high moisture content, which is a disincentive for most thermal processes particularly pyrolysis. However, it has been suggested that heat from the combustion of methane (gas obtained from the biochemical processing of breweries' waste water) may be used to dehydrate wet BSG.

The imperceptible "shoulder" between 473 and $543 \mathrm{~K}$ corresponds to hemicellulose degradation, while the prominent peak at about $600 \mathrm{~K}$ may be attributed to cellulose decomposition. This trend agrees with previous findings in literature [39]. The DTG thermogram for extractive-free BSG showed a shift toward higher temperature. This is an indication that the extractive-free BSG has a relatively higher thermal stability, thus, delaying the onset of thermal decomposition. The linear plots in Figs. 2 A, 3 A, 2 B and 3 B were derived from the application of Eqs. (2) and (3) respectively. Table 2 presents the apparent activation energy and confidence interval values for BSG and extractive-free BSG obtained from the linear plots for the limits of the conversion ratio under consideration.

The kinetic data study was limited to the conversion ratio of $0.1-0.8$ because outside this limits the correlation was poor. Probably, this is an indication of the inadequacy of the kinetic chemical models as the thermal decomposition process is not entirely a chemical-based reaction. The correlation coefficients obtained for the methods were fairly high, which attests to the reliability of the models [25]. Generally, the trends of the apparent activation energy for both methods and samples are fairly comparable; reaching a peak of 171.78 and $187.73 \mathrm{~kJ} \mathrm{~mol}^{-1}$ (for BSG), and 261.05 and $234.23 \mathrm{~kJ} \mathrm{~mol}^{-1}$ (for extractive-free BSG) respectively for Friedman's and Starink's.The apparent activation energy obtained for both methods were within the range reported for biomass residues $[36,40]$. For both BSG and extractive-free BSG, the average value of the apparent activation energy returned by Friedman's model was comparatively higher than Starink's; this is similar to an earlier observation made in literature [24]. It is noteworthy that the apparent activation energy values obtained for extractive-free BSG were relatively higher than those for BSG. This may be as a result of the absence of the lipids and other light organic volatiles (extractives), which have been noted to accelerate the degradation process in biomass material $[40,41]$.

Table 2 clearly demonstrates continuous change in the apparent activation energy $E_{a}$ as conversion progresses. This is a common occurrence in biomass decomposition kinetics due to the heterogeneous character of biomass polymeric composition. The trend of $E_{a}$ may be broadly categorized into three regions. Firstly, at $\alpha \leq 0.2$ and temperature of about $600 \mathrm{~K}$, an $E_{a}<175 \mathrm{~kJ} \mathrm{~mol}^{-1}$ was obtained. This is in agreement with values obtained for biomass in literature [40]. The decomposition of hemicellulose fractions is largely contributory 




Fig. 1. TGA and DTG thermograms of BSG and extractive (Ext)-free BSG residues at $20 \mathrm{~K} / \mathrm{min}$.
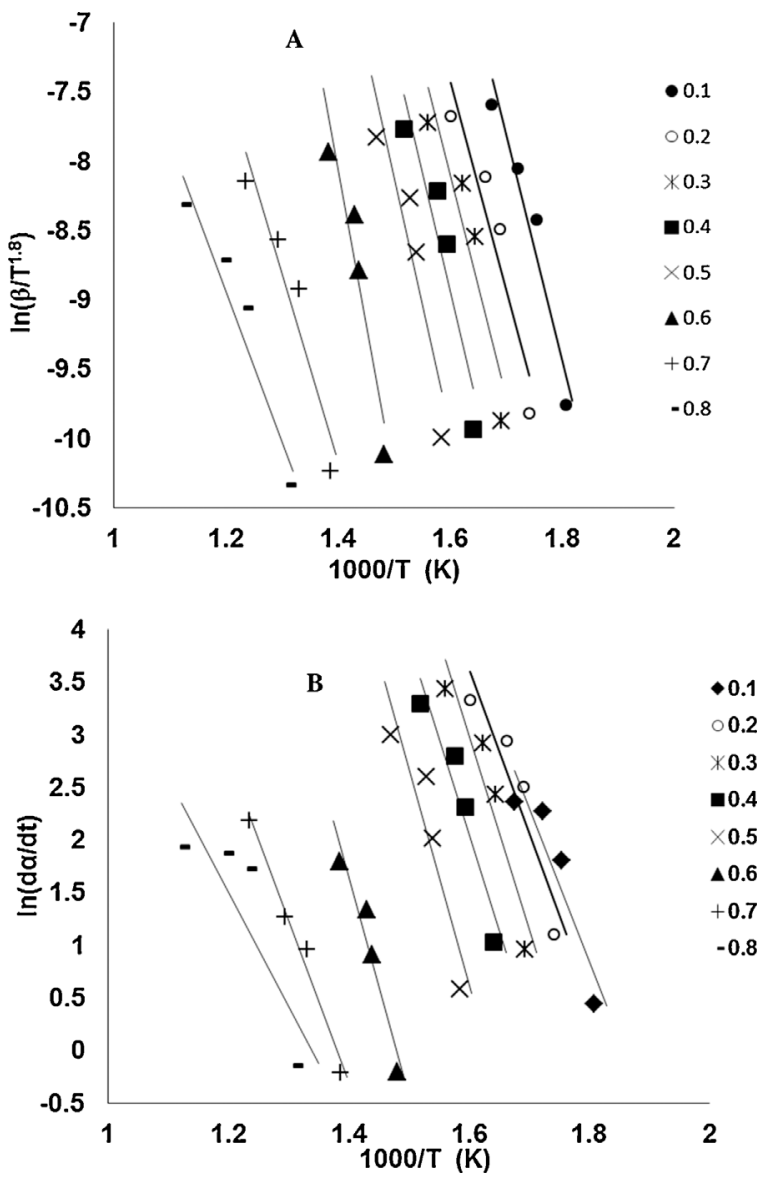

Fig. 2. Linear plots for (A) integral and (B) differential methodsof BSG.

because of its high reactivity, which is responsible for low activation energy. Secondly, the $E_{a}$ rises steadily for all the samples and reaches a peak at $\alpha=0.6$. The collective input of the three polymeric constituents is highly likely at this stage, though at varying degrees. However, the contribution of cellulose is of particular importance because of its highly ordered crystalline structure that confers on it high thermal stability [40]. At the third stage, the $E_{a}$ deeps, as the degradation of lignin and products of secondary reactions linger on. From the foregoing, biomass thermal degradation proceeds on an intricate successive, parallel, and competitive reaction pathways. Thus biomass decomposition kinetics is better explained as a multi-step reaction
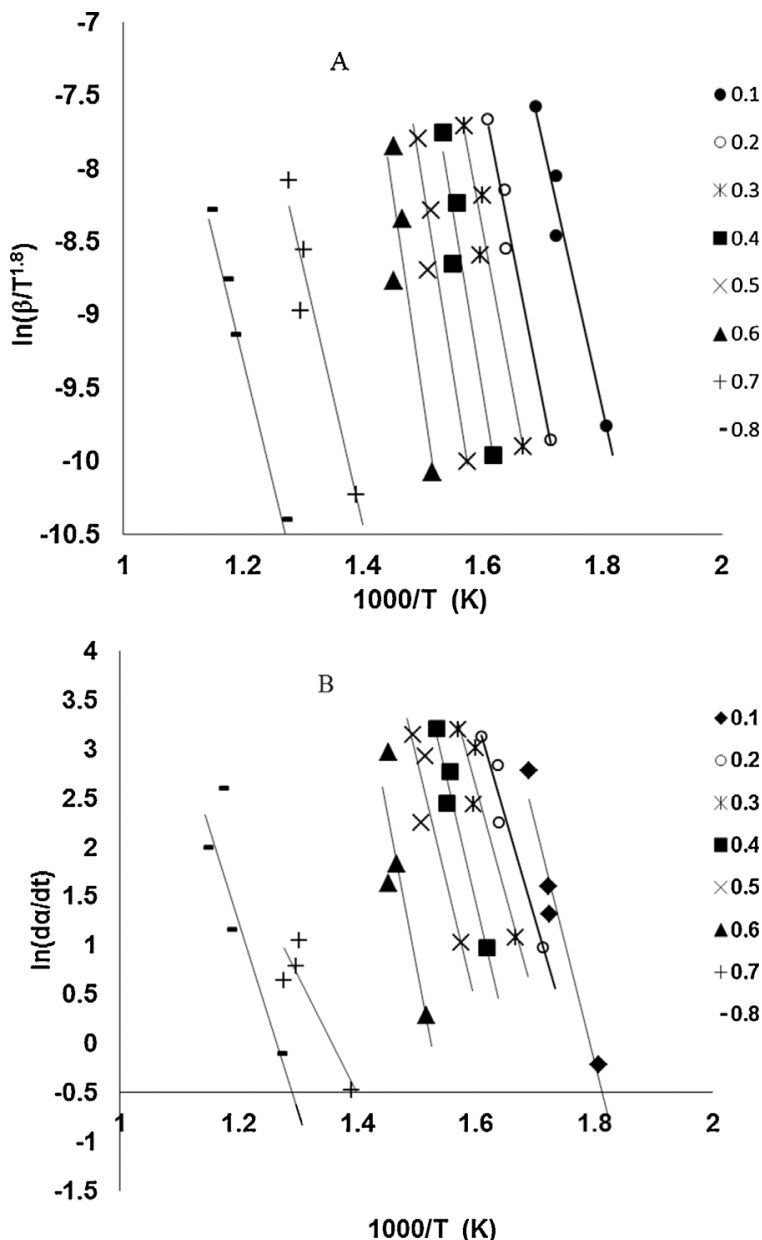

Fig. 3. Linear plots for (A) integral and (B) differential methods of extractive-free BSG.

mechanism

\subsection{FTIR, Raman spectroscopy and XRD analysis}

XRD analysis of BSG (Fig. 4) showed a typical XRD pattern of cellulose I with $2 \theta$ peaks at $13^{\circ}$ and $22^{\circ}$ which were assigned to the planes of (101) and (002), respectively [6]. XRD confirmed the presence of cellulose in BSG. CCI was determined for BSG at 0.70 which was a lot higher than that reported by do Santos et al. at 0.27 [6]. This difference 
Table 2

Apparent activation energy $\left(E_{a}\right)$ and correlation coefficients for conversion ratio of $0.10-0.80$ for BSG and extractive-free BSG.

\begin{tabular}{|c|c|c|c|c|c|c|c|c|}
\hline \multirow[t]{2}{*}{$\alpha(-)$} & \multicolumn{3}{|c|}{ Starink's $\left(E_{a}, \mathrm{~kJ} \mathrm{~mol}^{-1}\right)$} & \multicolumn{5}{|c|}{ Friedman's $\left(E_{a}, \mathrm{~kJ} \mathrm{~mol}^{-1}\right)$} \\
\hline & BSG & $\mathrm{R}^{2}$ & Extractive-free BSG & $\mathrm{R}^{2}$ & BSG & $\mathrm{R}^{2}$ & Extractive-free BSG & $\mathrm{R}^{2}$ \\
\hline 0.10 & $134.6 \pm 1.3$ & 0.941 & $152.8 \pm 1.3$ & 0.970 & $121.7 \pm 0.8$ & 0.856 & $199.5 \pm 1.7$ & 0.952 \\
\hline 0.20 & $125.2 \pm 1.3$ & 0.894 & $172.3 \pm 1.3$ & 0.971 & $129.7 \pm 0.8$ & 0.877 & $172.0 \pm 1.3$ & 0.943 \\
\hline 0.30 & $132.3 \pm 1.3$ & 0.877 & $184.1 \pm 1.3$ & 0.954 & $152.7 \pm 0.9$ & 0.889 & $183.5 \pm 1.3$ & 0.916 \\
\hline 0.40 & $144.4 \pm 1.3$ & 0.883 & $205.6 \pm 1.3$ & 0.930 & $152.2 \pm 0.8$ & 0.906 & $213.7 \pm 1.3$ & 0.956 \\
\hline 0.50 & $152.2 \pm 1.3$ & 0.858 & $213.2 \pm 1.3$ & 0.925 & $170.3 \pm 0.9$ & 0.841 & $208.2 \pm 1.3$ & 0.868 \\
\hline 0.60 & $186.7 \pm 1.3$ & 0.909 & $234.2 \pm 1.3$ & 0.807 & $171.8 \pm 0.7$ & 0.925 & $261.1 \pm 1.5$ & 0.751 \\
\hline 0.70 & $112.8 \pm 1.2$ & 0.907 & $147.4 \pm 1.3$ & 0.927 & $128.3 \pm 0.8$ & 0.981 & $100.0 \pm 0.9$ & 0.801 \\
\hline 0.80 & $89.6 \pm 1.2$ & 0.926 & $139.3 \pm 1.3$ & 0.990 & $90.4 \pm 0.8$ & 0.731 & $160.1 \pm 1.6$ & 0.784 \\
\hline Average & $134.7 \pm 1.3$ & & $181.1 \pm 1.3$ & & $139.7 \pm 0.8$ & & $187.3 \pm 1.4$ & \\
\hline
\end{tabular}

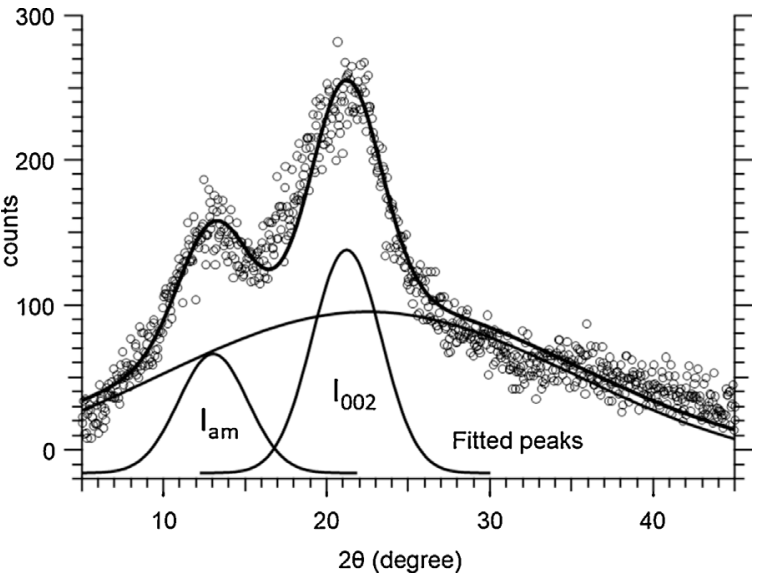

Fig. 4. X-ray diffractogram of BSG showing fitted peaks for cellulose $\mathrm{I}_{\mathrm{am}}$ and $\mathrm{I}_{002}$.

in CCI could be attributable to a (i) higher cellulose content $(\approx 26 \%)$ in this study (Table 1) as against (22\%) [6] and (ii) better resolved XRD for BSG showing defined peaks for $\mathrm{I}_{\mathrm{am}}$ and $\mathrm{I}_{002}$ in which intensities values could be easily determined than the broad unresolved XRD pattern for BSG of Santos et al. [6]. Cellulose in BSG can be used to produce levoglucosan, a valuable chemical building block, via pyrolysis.

FTIR spectroscopy is a useful charactersation tool that provides a means for the identification of the functional groups in biomass samples. Fig. 5 presents the FTIR spectra of BSG biomass and its corresponding biochar.

Evidently lignocellulosic biomass resources are susceptible to structural and chemical modifications once they undergo thermochemical decomposition processes. There are specific peaks on the FTIR spectra that could be used to monitor these modifications. Generally, peaks showed a sharp drop in intensities for the bio-char and in some instances they disappeared completely. The apparent reduction in the $\mathrm{OH} / \mathrm{NH}$ peak intensity at about $3300 \mathrm{~cm}^{-1}$ arises from the loss of hydroxyl and amine groups due to the dehydration/thermal process. The

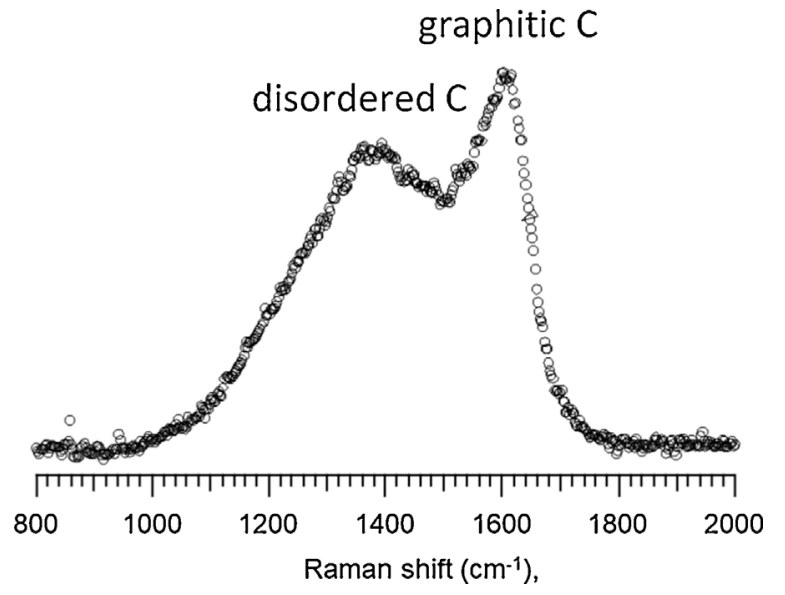

Fig. 6. Raman spectrum of BSG biochar.

Table 3

Compounds identified and quantified by GC/MS analysis of FAMEs derivatives.

\begin{tabular}{llll}
\hline COMPOUND & $\mathrm{M}^{+}(m / z)$ & RT (min) & \% of Extract \\
\hline Palmitic acid C16:0 & 270 & 31.91 & 15.8 \\
Linoleic acid C18:2 & 294 & 35.11 & 38.7 \\
Oleic acid C18:1 & 296 & 35.20 & 19.5 \\
Stearic acid C18:0 & 298 & 35.68 & 1.2 \\
Other compounds & & & 24.8 \\
\hline
\end{tabular}

amide I and II bands also decreased upon pyrolysis suggesting degradation of protein. The band intensities between 1200 and $1000 \mathrm{~cm}^{-1}$ are characteristic of stretching vibrations arising from the functional groups usually associated with hemicellulose and cellulose. Though these bands were prominent on the BSG spectrum, they were conspicuously absent on the bio-char's. There are apparent structural changes which has conferred some unique functional groups on the biochar surface. It has been noted that the presence of these functional groups enhances its adsorption capability and also serves as nutrient

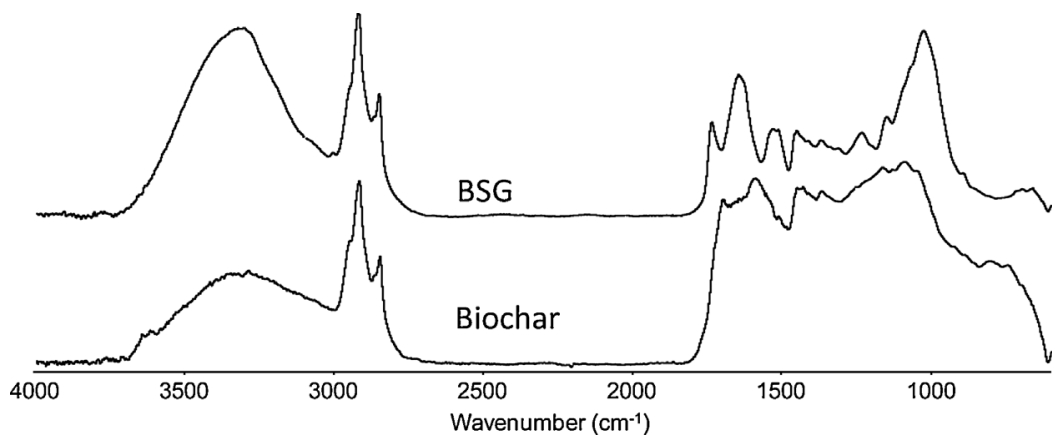

Fig. 5. FTIR spectra of BSG biomass and biochar. 
Table 4

Analytical Py-GC/MS of BSG, $\mathrm{CH}_{2} \mathrm{Cl}_{2}$ extracted BSG, and BSG $\mathrm{CH}_{2} \mathrm{Cl}_{2}$ extract showing retention time, molecular ion, compounds and\% peak area.

\begin{tabular}{|c|c|c|c|c|c|}
\hline Retention time (min) & Compound & $\mathrm{M}^{+}(m / z)$ & $\begin{array}{l}\text { BSG Peak Area } \\
(\%)\end{array}$ & $\begin{array}{l}\text { Ext-free BSG } \\
(\%)\end{array}$ & $\begin{array}{l}\text { BSG } \mathrm{CH}_{2} \mathrm{Cl}_{2} \text { extract } \\
(\%)\end{array}$ \\
\hline 1.29 & $\mathrm{CO}_{2}$ & 44 & 9.4 & 14.3 & 3.0 \\
\hline 1.49 & Furfuran & 68 & 3.6 & 2.2 & \\
\hline 1.56 & $\mathrm{C}_{6} \mathrm{H}_{12}$ & 86 & & & 0.5 \\
\hline 1.84 & acetic acid & 60 & 4.9 & 4.8 & \\
\hline 2.15 & Isovaleraldehyde & 86 & 0.3 & 1.0 & \\
\hline 2.21 & 1-Hydroxy-2-propanone & 74 & 1.1 & & \\
\hline 2.48 & pentene-diol & 104 & 0.4 & & \\
\hline 2.64 & Furaldehyde & 96 & 0.2 & 0.5 & \\
\hline 3.2 & Pyrrole & 67 & 0.3 & & \\
\hline 3.46 & Toluene & 92 & 1.6 & 2.3 & \\
\hline 3.77 & methyl pyruvate & 102 & 0.7 & 0.3 & \\
\hline 3.95 & 2-butyl-1-methyl-pyrrolidine & 84 & 0.6 & & \\
\hline 3.99 & 1,2 cyclopentanediol & 102 & 0.6 & & \\
\hline 4.48 & methyl urea + unknown & $74+110$ & 0.3 & & \\
\hline 4.68 & 2-furaldehyde & 96 & 1.4 & 2.4 & \\
\hline 4.81 & 5-pyrimidinol & 96 & 0.4 & & \\
\hline 5.21 & furfuryl alcohol & 98 & 0.5 & 1.6 & \\
\hline 5.49 & 5-hydroxy-hexan-2-one & 116 & 0.8 & & \\
\hline 6.06 & Styrene & 104 & 0.3 & 0.3 & \\
\hline 6.63 & $2(5 \mathrm{H})$-furanone & 84 & 0.3 & & \\
\hline 6.81 & 4-methyl-1-heptane & 112 & 0.4 & & \\
\hline 6.94 & 2-hydroxy-cyclopent-2-ene-1-one & 98 & 1.0 & & \\
\hline 7.78 & phloroglucitol & 132 & 0.4 & & \\
\hline 7.99 & hexahydro-3,6-pyridazinedione +5 -methyl-2-furaldehyde & $114+110$ & 1.4 & 1.5 & \\
\hline 8.43 & 2-methyl-2-cyclohexene-1-ol & 110 & 0.3 & & \\
\hline 8.64 & phenol & 94 & 0.3 & & \\
\hline 8.81 & nonenoic acid & 138 & 0.4 & & \\
\hline 9.05 & 4-hydroxy-5,6-dihydro-(2H)-pyran-2-one & 114 & 4.3 & 3.9 & \\
\hline 9.86 & 2-hydroxy-1-methyl-1-cyclopenten-3-one & 112 & 0.3 & 0.3 & \\
\hline 10.34 & 3-methyl-tetrahydrofuran-2,4-dione + 2,3-dihydro-benzofuran & $114+120$ & 1.0 & 0.2 & \\
\hline 11.33 & methyl phenol & 108 & 1.5 & 1.2 & \\
\hline 11.56 & 2 -furoic acid methyl ester +4 -hydroxy-2,5-dimethyl-3(2H)-furanone & $126+128$ & 0.4 & & \\
\hline 11.7 & guaiacol & 124 & 0.2 & & \\
\hline 11.8 & unknown fatty alcohol? & 124 & 0.1 & & \\
\hline 12.64 & $\begin{array}{l}4(1 \mathrm{H}) \text {-pyridone }+ \text { (4-hydroxy-3-methyl-(5H)-furanone or 3-methyl-2,4- } \\
\text { furandione) }\end{array}$ & $95+114$ & 1.0 & & \\
\hline 14.48 & 1,5-anhydro-pentose $+3,5$-dihydroxy-2-methyl-4-pyrone & $132+142$ & 5.8 & & \\
\hline 14.71 & methyl guaiacol & 138 & 0.3 & 0.6 & \\
\hline 15.18 & 1,4:3,6-dianhydro-hexopyranose & 144 & 0.2 & 6.0 & \\
\hline 15.5 & vinyl phenol & 120 & 1.1 & & \\
\hline 17.13 & 4-ethyl guaiacol $+1,5$-anhydro-pentose & $152+132$ & 3.5 & & \\
\hline 17.54 & indolizine & 117 & 0.4 & & \\
\hline 17.95 & 2-hydroxymethy-5-hydroxy-2,3-dianhydro-(4H)-pyran-4-one & 144 & 0.9 & & \\
\hline 18.08 & 4-vinyl guaiacol & 150 & 3.0 & 3.5 & \\
\hline 19.06 & syringol & 154 & 0.1 & & \\
\hline 19.99 & 3-methyl-1H-indole & 131 & 0.2 & & \\
\hline 20.34 & vanillin & 152 & 0.2 & & \\
\hline 21.52 & methyl-syringol & 168 & 0.2 & & \\
\hline 21.60 & cis-isoeugenol & 164 & 0.3 & & \\
\hline 23.47 & levoglucosan & 162 & 11.5 & 40.5 & \\
\hline 24.40 & vinyl-syringol & 180 & 0.2 & & \\
\hline 27.49 & cis-4-propenyl-syringol & 194 & 0.1 & 4.3 & \\
\hline 28.34 & trans-isoeugenol & 164 & 0.2 & & \\
\hline 28.74 & myristic acid & 228 & 0.3 & & \\
\hline 32.38 & 5,10-diethoxy-2,3,7,8-tetrahydro-1H,6H-dipyrrolo $\left[1,2-1 ; 1^{\prime}, 2^{\prime}-d\right]$ pyrazine & 194 & 0.5 & & \\
\hline 32.94 & palmitic acid & 256 & 13.4 & 3.2 & 51.0 \\
\hline 33.98 & $\mathrm{C}_{11} \mathrm{H}_{12} \mathrm{O}_{3}$ & 192 & 0.2 & & \\
\hline 36.04 & linoleic acid & 280 & 4.2 & 3.0 & 9.8 \\
\hline 36.15 & oleic acid & 282 & 5.2 & & 14.2 \\
\hline 36.52 & stearic acid & 284 & 1.0 & & 5.7 \\
\hline 36.81 & C18:2 fatty acid & 280 & 0.1 & & 12.3 \\
\hline 38.01 & palmitic acid monoglyceride & 330 & 0.4 & & 1.3 \\
\hline 38.20 & sinapyl-aldehyde & 208 & 0.2 & & \\
\hline 40.14 & 3-benzylhexahydropyrrolo-[1,2-a]pyrazine-1,4-dione & 244 & 0.2 & & \\
\hline 42.82 & mono(2-ethylhexyl)phthlate & 278 & 0.2 & & \\
\hline 44.42 & 7-(3,4methylenedioxy)-tetrahydrobenzofuranone & 272 & 0.4 & & \\
\hline 46.89 & squalene & 410 & 0.1 & & \\
\hline 47.81 & cholesta-3,5-diene & 368 & 0.3 & & \\
\hline 48.74 & stigmastan-3,5-diene $\mathrm{C}_{29} \mathrm{H}_{48}$ & 396 & 0.1 & & 2.1 \\
\hline 49.30 & steroid $\mathrm{C}_{27} \mathrm{H}_{42} \mathrm{O}$ & 382 & 0.2 & & \\
\hline 50.05 & stigmastan-diene $\mathrm{C}_{29} \mathrm{H}_{48}$ & 396 & 0.1 & & \\
\hline 50.22 & $\mathrm{C}_{29} \mathrm{H}_{46}$ steroid & 394 & 0.2 & & \\
\hline 50.49 & stigmastan-diene $\mathrm{C}_{29} \mathrm{H}_{48}$ & 396 & 0.7 & & \\
\hline
\end{tabular}


Table 4 (continued)

\begin{tabular}{|c|c|c|c|c|c|}
\hline Retention time (min) & Compound & $\mathrm{M}^{+}(m / z)$ & $\begin{array}{l}\text { BSG Peak Area } \\
(\%)\end{array}$ & $\begin{array}{l}\text { Ext-free BSG } \\
(\%)\end{array}$ & $\begin{array}{l}\text { BSG } \mathrm{CH}_{2} \mathrm{Cl}_{2} \text { extract } \\
(\%)\end{array}$ \\
\hline 50.72 & $\mathrm{C}_{29} \mathrm{H}_{46}$ steroid & 394 & 0.2 & & \\
\hline 52.14 & campesterol & 400 & 0.1 & & \\
\hline 53.37 & c-sitosterol & 414 & 0.3 & 2.1 & \\
\hline 53.87 & hexadecyl-palmitate & 480 & 0.1 & & \\
\hline 54.83 & a-saccharostenone & 410 & 0.1 & & \\
\hline
\end{tabular}

exchange sites [42]. Therefore they may be applied as either a contaminant adsorbent and/or soil fertility improvement medium. An increase in crystallinity was noted as revealed by the variation in the TCI value (from 0.4; BSG to 3.0; bio-char). This may be as a result of removal of amorphous components from BSG and some crystallisation of cellulose molecules in the quasi-crystalline domain [33]. The CI, as a semi-quantitative tool, could be employed to assess the measure of cross-linking in lignin during char formation. A significant change in the CI value was observed in this study; from 1.2 for BSG to 2.2 for biochar. This implies that an appreciable degree of lignin cross-linking had occurred during pyrolysis and this is in consonance with findings from literature $[17,33]$. Biochar from agricultural residues produced at about $500{ }^{\circ} \mathrm{C}$ has been reported to possess a high quantity of recalcitrant $\mathrm{C}$ fraction $[42,43]$. This biochar condition is favourable for carbon sequestration in soils.

Raman spectroscopy was performed to obtain information on the carbon (C) structure of this biochar (Fig. 6). An estimation of disordered carbon in the sample was calculated from the ratio of $\mathrm{D}$ (disordered, $1380 \mathrm{~cm}^{-1}$ )/G (graphitic, $1605 \mathrm{~cm}^{-1}$ ) band intensities $\left(\mathrm{I}_{\mathrm{D}} / \mathrm{I}_{\mathrm{G}}\right)$ to be 0.8 . The $\mathrm{I}_{\mathrm{D}} / \mathrm{I}_{\mathrm{G}}$ value obtained was in the range of values for biochar (0.8-1.5) from various biomasses pyrolyzed around $500{ }^{\circ} \mathrm{C}[32,44]$. These results show that the BSG biochar has a reasonable amount of disordered amorphous carbon. This amorphous character serves as an incentive for mineralisation by bacteria and fungi that are critical to nutrient turnover processes and aggregate formation [44].

\subsection{GC/MS analysis of FAMEs derivatives obtained from BSG's extracts}

Extracts from lignocellulosic biomass are rich sources of lipids (of which fatty acids are among the constituents) that are valuable for several valorisation purposes. Table 3 shows the content of the derivatised $\mathrm{CH}_{2} \mathrm{Cl}_{2}$ extracts with a total of four lipids detected. The lipids extractable by solvent are often limited because some of the lipids are intricately bound to the vast polymeric network. It was observed that linoleic acid (38.7\%), oleic (19.5\%), and palmitic (15.8\%) acids had the highest quantity. This agrees with data reported in an earlier publication as linoleic particularly recorded the highest quantity [12,7].

Fatty acids are valuable sources of phytochemicals that could be deployed in nutraceutical applications and in the production of cosmetics. It has been suggested that BSG is a probable source of resins, which could be applied in the production of bio-lubricants $[3,12]$.

\subsection{Analytical Py-GC/MS of BSG, extractive-free $B S G$ and $B S G \mathrm{CH}_{2} \mathrm{Cl}_{2}$ extracts at $500^{\circ} \mathrm{C}$}

Traditionally, the thermochemical decomposition of lignocellulosic biomass leads to a liberation of a wide variety of volatile organic compounds. These compounds are usually from the thermal cracking of hemicellulose, cellulose and lignin fractions. The analytical Py-GC/MS provides a veritable means to prospect the various chemical compounds that may be present in the liquid yield produced from thermal degradation processes. Table 4 presents the chemical compounds detected by the Py-GC/MS analysis of BSG, extractive-free BSG and BSG extract. The compounds found at the earliest stage of decomposition in significant quantity for both BSG and extractive-free BSG include furfuran, acetic acid, toluene, and 2-furaldehyde. Most of these are products of hemicellulose breakdown. Noticeably, the concentration of levoglucosan in the extractive-free BSG (40.5\%) was about three and half times that in BSG (11.5\%). Levoglucosan is an intermediate product from the decomposition of cellulose. Some of the constituents of the extractives may have being responsible for the disparity because it has been reported that the presence of inorganic minerals influences the liberation of levoglucosan [39]. Apparently, fatty acids were the only compounds detected in $\mathrm{BSG} \mathrm{CH}_{2} \mathrm{Cl}_{2}$ extracts with palmitic acid (51.0\%) recording the highest concentration. This is expected since the extracts do not contain any of the polymeric fractions. It is also noteworthy that palmitic and linoleic acids were present in all the three samples in appreciable amount. This also affirms the possibility of bio-diesel production from the liquid product yield as well. The phenolic compounds, products of lignin deconstruction, found in concentrations between 1.2 and 3.5\% for BSG and ext-free BSG were methyl phenol and 4-vinyl guaiacol.

The influence of BSG heterogeneous character in thermal decomposition processes is again apparent as the concentration of levoglucosan in the extr-free BSG (40.5\%) was about three and half times that in BSG (11.5\%). Levoglucosan is an intermediate product from the decomposition of cellulose. Some of the constituents of the extractives may have being responsible for the disparity because it has been reported that the presence of inorganic minerals influences the liberation of levoglucosan [39]. In addition, the number of detectable chemical compounds in the BSG was much higher than those of ext-free BSG. This may be another pointer to the intricacy involved in a thermal degradation process with the presence or otherwise of certain chemical species.

\section{Conclusion}

Analytical pyrolysis experiment at $500{ }^{\circ} \mathrm{C}$ was conducted on brewer's spent grains collected from a Nigerian brewery. The data from the study showed that BSG possesses the physical and chemical properties that make it suitable as a lignocellulosic feedstock for both thermal decomposition and biochemical processes. Biochar from thermal degradation of BSG has a potential for carbon sequestration and soil amendment applications. Among the saturated fatty acids identified palmitic, linoleic and oleic acids, were the most predominant making both the BSG extractives and the liquid product from thermal decomposition a potential feedstock for renewable diesel or biodiesel production. Significantly, the prospect of extracting levoglucosan, a building block for producing polymers and a feedstock for fermentation, has been demonstrated.

\section{References}

[1] K. Vanreppelen, S. Vanderheyden, T. Kuppens, S. Schreurs, J. Yperman, R. Carleer, Activated carbon from pyrolysis of brewer's spent grain: production and adsorption properties, Waste Manage. Res. 32 (2014) 634-645.

[2] D. Deconinck, L. Capon, B. Clerinx, J. Couder, Indicatorenvoorduurzameontwikkeling in de BelgischeIndustrie T. e. C. A. DWTC Federale Dienstenvoor Wetenschappelijke. Belgium, POD Wetenschapsbeleid 74 (2001).

[3] S.I. Mussatto, G. Dragone, I.C. Robert, Brewers' spent grain: generation, characteristics and potential applications, J. Cereal Sci. 43 (2006) 1-14.

[4] Meristem, Breweries Sector Report, (2014) http://www.meristem.com.ng/uploads/ files $/ 2014 \% 20$ Breweries\%20Sector\%20report.pdf . (Accessed on 22 December 
2016).

[5] U. Ben-hamed, H. Seddighi, K. Thomas, Economic returns of using brewery's spent grain in animal feed, Int. Sch. Sci. Res. Innov. 5 (2011) 142-145.

[6] D.M. dos Santos, A. de Lacerda Bukzem, D.P.R. Ascheri, R. Signini, G.L.B. de Aquino, Microwave-assisted carboxymethylation of cellulose extracted from brewer's spent grain, Carbohydr. Polym. 131 (2015) 125-133.

[7] P. Niemi, T. Tamminen, A. Smeds, K. Viljanen, T. Ohra-aho, U. Holopainen-Mantila, C.B. Faulds, K. Potanen, J. Buchert, Characterization of lipids and lignans in Brewer's spent grain and its enzymatically extracted fraction, J. Agric. Food Chem. 60 (2012) 9910-9917.

[8] W. Qu, Z. Mou, H. Cui, Z. Zhang, Analysis of fatty acids in A: szechenyianum gay. by microwave-assisted extraction and gas chromatography-mass spectrometry, Phytochem. Anal. 22 (2011) 199-204.

[9] E. Martinez-Guerra, V.G. Gude, A. Mondala, W. Holmes, R. Hernandez, Microwave and ultrasound enhanced extractive-Transesterification of algal lipids, Appl. Energy 129 (2014) 354-363.

[10] A. Patel, D.K. Sindhu, N. Arora, R.P. Singh, V. Pruthi, P.A. Pruthi, Biodiesel production from non-edible lignocellulosic biomass of Cassia fistula L: fruit pulp using oleaginous yeast Rhodosporidium kratochvilovae HIMPA1, Bioresour. Technol. 197 (2015) 91-98.

[11] W. Li-bing, Y. Hai-yan, H. Xiao-hui, L. Rui-ying, Influence of fatty acid composition of woody biodiesel plants on the fuel properties, J. Fuel Chem. Technol. 40 (2012) 397-404.

[12] Xiang T., Amin R.A.M., 2011. Water-Based Mud Lubricant using Fatty Acid Polyamine Salts and Fatty Acid Esters, United States patent US 20110036579.

[13] A.M. Celaya, T.L. Amanda, L.G. Jillian, Co-combustion of brewer's spent grains and Illinois No. 6 coal: impact of blend ratio on pyrolysis and oxidation behavior, Fuel Process. Technol. 129 (2015) 39-51.

[14] J.L. Goldfarb, S. Ceylan, Second-generation sustainability: application of the distributed activation energy model to the pyrolysis of locally sourced biomass-coal blends for use in co-firing scenarios, Fuel 160 (2015) 297-308.

[15] J. Speight, Synthetic Fuels Handbook: Properties, Process and Performance, McGraw-Hill Professional, New York, NY, USA, 2008.

[16] A. Sanna, S. Li, R. Linforth, K.A. Smart, J.M. Andresen, Bio-oil and biochar from low temperature pyrolysis of spent grains using activated alumina, Bioresour. Technol. 102 (2011) 10695-10703.

[17] S. Liang, Y. Han, L. Wei, A.G. McDonald, Production and Characterization of bio-oil and bio-char from Pyrolysis of Potato Peel Wastes, Biomass Convers. Biorefin. 5 (2015) 237-246.

[18] M. Becidan, $\varnothing$. Skreiberg, J.E. Hustad, $\mathrm{NO}_{\mathrm{x}}$ and $\mathrm{N}_{2} \mathrm{O}$ precursors $\left(\mathrm{NH}_{3}\right.$ and $\left.\mathrm{HCN}\right)$ in pyrolysis of biomass residues, Energy Fuels 21 (2007) 1173-1180.

[19] T. Dickerson, J. Soria, Catalytic fast pyrolysis: a review, Energies 6 (2013) 514-538.

[20] Y. Han, D.N. McIlroy, A.G. McDonald, Hydrodeoxygenation of pyrolysis oil for hydrocarbons production using nanosprings based catalysts, J. Anal. Appl. Pyrolysis 117 (2016) 94-105, http://dx.doi.org/10.1016/j.jaap.2015.12.011.

[21] B. Pecha, M. Garcia-Perez, Pyrolysis of lignocellulosic biomass: oil, char, and gas, in: A. Dahiya (Ed.), Bioenergy, Elsevier, Inc, 2015, pp. 413-442, , http://dx.doi. org/10.1016/B978-0-12-407909-0.00026-2.

[22] A.O. Balogun, O.A. Lasode, A.G. McDonald, Thermo-analytical and physico-chemical characterization of woody and non-woody biomass from an agro-ecological zone in Nigeria, BioResources 9 (2014) 5099-5113.

[23] S.V. Vassilev, D. Baxter, L.K. Andersen, C.G. Vassileva, An overview of the chemical composition of biomass, Fuel 89 (2010) 913-933.

[24] A.O. Balogun, O.A. Lasode, L. Hui, A.G. McDonald, Fourier transform infrared (FTIR) study and thermal decomposition kinetics of Sorghum bicolour glume and Albizia pedicellaris residues, Waste Biomass Valoris. 6 (2015) 109-116.

[25] M.A. Lopez-Velaquez, V. Santes, J. Balmaseda, E. Torres-Garcia, Pyrolysis of orange waste: a thermo-kinetic study, J. Anal. Appl. Pyrolysis 99 (2013) 170-177.

[26] L. Burhenne, J. Messmer, T. Aicher, M. Laborie, The effects of the biomass components lignin, hemicellulose and cellulose on TGA and fixed-bed pyrolysis, J. Anal. Appl. Pyrolysis 101 (2013) 177-184.

[27] A.M. da Silva, A.P.M. Tavares, C.M.R. Rocha, R.O. Cristóväo, J.A. Teixeira, E.A. Macedo, Immobilization of commercial laccase on spent grain, Process Biochem. 47 (2012) 1095-1101.

[28] A.I. Ferraz, C. Amorim, T. Tavares, J.A. Teixeira, Chromium (III) biosorption onto spent grains residual from brewing industry: equilibrium, kinetics and column studies, Int. J. Sci. Environ. Technol. 12 (2015) 1591-1602.

[29] A. Montusiewicz, S. Pasieczna-Patkowska, M. Lebiocka, A. Szaja, M. SzymańskaChargot, Hydrodynamic cavitation of brewery spent grain diluted by wastewater, Chem. Eng. J. (2016), http://dx.doi.org/10.1016/j.cej.2016.10.132.

[30] X. Xi, J. Yan, G. Quan, L. Cui, Removal of the pesticide pyrmetrozine from aqueous solution by biochar produced from brewer's spent grain at different pyrolytic temperatures, BioResources 9 (2014) 7696-7709.

[31] M. McDonald-Wharry, M. Manley-Harris, K. Pickering, Carbonisation of biomassderived chars and the thermal reduction of a grapheme oxide sample studied using Raman spectroscopy, Carbon 59 (2013) 383-405.

[32] L. Wei, N. Stark, A.G. McDonald, Interfacial improvements in biocomposites based on poly(3-hydroxybutyrate) and poly(3-hydroxybutyrate-co-3-hydroxyvalerate) bioplastics reinforced and grafted with $\alpha$-cellulose fibers, Green Chem. 17 (2015) 4800-4814.

[33] A.O. Balogun, O.A. Lasode, A.G. McDonald, Thermo-physical, chemical and structural modifications in torrefied biomass residues, Waste Biomass Valorization (2016), http://dx.doi.org/10.1007/s12649-016-9787-7.

[34] S. Vyazovkin, K. Chrissafis, M.L. Di Lorenzo, N. Koga, M. Pijolat, B. Roduitf, N. Sbirrazzuoli, J.J. Suñol, ICTAC Kinetics Committee recommendations for collecting experimental thermal analysis data for kinetic computations, Thermochim. Acta 590 (2014) 1-23.

[35] J.A. Soria, A.G. McDonald, Liquefaction of softwoods and hardwoods in supercritical methanol: a novel approach to bio-oil production, in: C. Baskar, S. Baskar, R.S. Dhillon (Eds.), Biomass Conversion: the Interface of Biotechnology, Chemistry and Materials Science, Springer, Berlin, 2012, pp. 421-433.

[36] A.O. Balogun, O.A. Lasode, A.G. McDonald, Devolatilisation kinetics and pyrolytic analyses of Tectona grandis (teak), Bioresour. Technol. 156 (2014) 57-62.

[37] M.J. Starink, A new method for the derivation of activation energies from experiments performed at constant heating rate, Thermochim. Acta 288 (1996) 97-104.

[38] C.A. Borges, G. Géczi, K. Kovács, M. Horváth, I. Bácskai, P. Korzenszky, Examination of energy recovery of brewer's spent grain I. -Chemical process, J. Microbiol. Biotechnol. Food Sci. 5 (2015) 116-119.

[39] O.A. Lasode, A.O. Balogun, A.G. Armando, Torrefaction of some nigerian lignocellulosic resources and decomposition kinetics, J. Appl. Anal. Pyrolysis 109 (2014) 47-55.

[40] M. Poletto, A.J. Zattera, R.M.C. Santana, Thermal decomposition of wood: kinetics and degradation mechanisms, Bioresour. Technol. 126 (2012) 7-12.

[41] M. Poletto, A.J. Zattera, M.M.C. Forte, R.M.C. Santana, Thermal decomposition of wood: influence of wood components and cellulose crystallite size, Bioresour. Technol. 109 (2012) 148-153.

[42] N.A. Qambrania, M.M. Rahmana, S. Wonc, S. Shima, C. Raa, Biochar properties and eco-friendly applications for climate change mitigation, waste management, and wastewater treatment: a review, Renew. Sustain. Energy Rev. 79 (2017) 255-273.

[43] A. Demirbas, Effect of temperature and particle size on biochar yield from pyrolysis of agricultural residues, J. Anal. Appl. Pyrolysis 72 (2004) 243-248.

[44] L. Zhao, X. Cao, A.Z.O. Masek, Heterogeneity of biochar properties as a function of feedstock sources and production temperatures, J. Hazard. Mater. 1 (-9) (2013) 256-257. 